\title{
Mass balance of emerging organic micropollutants in a small wastewater treatment plant
}

\author{
M. R. Boni ${ }^{1}$, S. Sbaffoni ${ }^{1}$, P. Tedesco ${ }^{1} \&$ M. Vaccari ${ }^{2}$ \\ ${ }^{I}$ Department of Civil and Environmental Engineering, SAPIENZA \\ University of Rome, Italy \\ ${ }^{2}$ Department of Civil Engineering, Architecture, \\ Land and Environment, University of Brescia, Italy
}

\begin{abstract}
Emerging organic micropollutants are compounds measured in water in $\mu \mathrm{g} / \mathrm{l}$ or ng/l which may have long-term negative effects on both wildlife and humans.

The purpose of this work was to perform a mass balance of emerging organic micropollutants on activated sludge tank and on secondary settling tank in a small wastewater treatment plant in the Municipality of Rome. The analytes

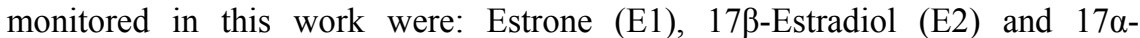
Ethinylestradiol (EE2) for steroid hormones, 4-Nonylphenol (4-NP) and Bisphenol A (BPA) for substituted Phenols and Alkylphenols, Amphetamine (AM), Methamphetamine (MET), Benzoylecgonine (BEG) and 11-nor- $\Delta$ 9-THC9carboxy (THC-COOH) for drugs of abuse.

Mass balance on activated sludge tank showed that the emerging organic micropollutants removed were BPA (59\%), EE2 (34\%), AM (56\%) and THC$\mathrm{COOH}(35 \%)$. The processes occurring in the secondary settling tank were able to reduce 4-NP (26\%), BPA (74\%), E1 (82\%), EE2 (93\%), AM (44\%), MET $(80 \%)$, BEG $(72 \%)$ and $\mathrm{THC}-\mathrm{COOH}(39 \%)$. The residual amount of each substance was distributed between the effluent, the return sludge line and the excess sludge.

Since the removal of emerging organic micropollutants was partial, the conventional wastewater treatment plant is not able to completely break down these substances. Accordingly, these compounds are found in water body potentially active and dangerous to wildlife and humans.

Keywords: alkylphenolos, drugs of abuse, endocrine disruptors, micropollutants, steroid hormones, wastewater treatment plant.
\end{abstract}




\section{Introduction}

The presence of emerging organic micropollutants in the water has long been the center of the international scientific debate. The term "micro" is commonly used to describe organic and inorganic compounds present in water in concentrations of $\mu \mathrm{g} / \mathrm{l}$ or $\mathrm{ng} / \mathrm{l}$. The definition of emerging organic micropollutants includes human and veterinary drugs, drugs of abuse, industrial products, home- and personal care products, other persistent organic compounds, steroid and thyroid hormones, phytoestrogens and other endocrine disruptors. Some compounds are endocrine disruptors, id est substances that interfere with normal functioning of the endocrine system and that can alter the normal growth, development, reproduction and behavior of organisms. The main potential effects resulting from exposure to endocrine disruptors are: hermaphroditism in fish, reproductive abnormalities and the feminization of fish; the latter represents the effect most noted in the literature (Mastroianni et al. [1]).

Drugs of abuse and their metabolites, instead, have recently been recognized as emerging contaminants (Richardson [2]). These compounds have become pseudo-persistent in the environment due to the high amount of production and use; furthermore they may exercise negative effects on ecosystems. However, at the time their ecotoxicity on aquatic fauna has not been investigated yet (Postigo et al. [3]).

The sources of release of micropollutants are manifold, both anthropogenic and natural, and not always detectable. In general, the sources of pollution are divided into two main categories: point and nonpoint or diffuse. Wastewater treatment plants (WWTPs) represent an important point source of emerging organic micropollutants (Stasinakis et al. [4]; Rosal et al. [5]), inasmuch not designed with the aim of removing these compounds. Removal of emerging organic micropollutants from the aqueous phase in WWTPs can be achieved through different mechanisms: biotic and abiotic degradation (Ren et al. [6]; Dialynas and Diamdopoulos [7]), adsorption to suspended solids (Ren et al. [6]) and/or on biomass (Dialynas and Diamdopoulos [7]), volatilization from liquid to gas phase (Dialynas and Diamdopoulos [7]), chemical oxidation (Bertanza et al. [8]; Dialynas and Diamdopoulos [7]). In particular, in an activated sludge process, removal is attributed to degradation by microorganisms and adsorption to suspended solids. In fact, it is more likely that bioadsorption and biodegradation interact in the bioreactor, although at the moment it is unclear the role of each mechanism. Furthermore, the removal mechanisms do not follow a general rule, as their relative contribution depends on the physical-chemical properties of micropollutants, the origin and composition of wastewater and sewage treatment plant operating parameters (Cirja et al. [9]).

The aim of this work was to perform a mass balance of emerging organic micropollutants on the activated sludge tank and on the secondary settler of a small wastewater treatment plant in the Municipality of Rome. The amounts removed by adsorption and/or by degradation, leaving the plant with the effluent and accumulated in the sludge were assessed. For this purpose a monitoring campaign of the concentrations of micropollutants incoming and outgoing the 
two treatment units has been conducted. Preliminarily the real HRT in the tanks was determined through two hydrodynamic tests, using Lithium Carbonate $\left(\mathrm{Li}_{2} \mathrm{CO}_{3}\right)$ as tracer, entered in pulse mode and monitored over time.

The analytes monitored in this work were: Estrone (E1), 17 $\beta$-Estradiol (E2) and $17 \alpha$-Ethinylestradiol (EE2) for steroid hormones; 4-Nonylphenol (4-NP) and Bisphenol A (BPA) for substituted Phenols and Alkylphenols; Amphetamine (AM), Methamphetamine (MET), Benzoylecgonine (BEG) and 11-nor- $\Delta 9-\mathrm{THC}$ 9carboxy (THC-COOH) for drugs of abuse.

\section{Materials and methods}

\subsection{Wastewater treatment plant}

The monitored WWTP is a Conventional Activated Sludge plant (designed size 9,000 p.e.) treating $657,000 \mathrm{~m}^{3} /$ year of domestic and industrial wastewater, with a maximum capacity of $1,800 \mathrm{~m}^{3} / \mathrm{d}$. The layout includes a basement storage tank, a pumping station, a hand-cleaned coarse screen, a grit removal, a degreasing unit, two oxidation-nitrification reactors (volume $700 \mathrm{~m}^{3}$ each, 2 parallel basins), two secondary settlers (volume $230 \mathrm{~m}^{3}$ each, 2 parallel basins), disinfection and sludge storage tank.

The sludge treatment line consists of an aerobic digester, a thickener and a belt-filter press.

Incoming wastewater and effluent characterization (average values obtained during the monitoring campaign) is reported in Table 1 (APHA [10]).

Table 1: Influent wastewater and effluent characteristics.

\begin{tabular}{|c|c|c|c|}
\hline \multicolumn{2}{|c|}{ Wastewater } & \multicolumn{2}{|c|}{ Effluent } \\
\hline COD & $420 \mathrm{mg} / 1$ & $\mathrm{COD}$ & $35 \mathrm{mg} / 1$ \\
\hline $\mathrm{BOD}_{5}$ & $240 \mathrm{mg} / 1$ & $\mathrm{BOD}_{5}$ & $8 \mathrm{mg} / \mathrm{l}$ \\
\hline SST & $380 \mathrm{mg} / 1$ & SST & $15 \mathrm{mg} / \mathrm{l}$ \\
\hline TKN & $50 \mathrm{mg} / \mathrm{l}$ & TKN & $21 \mathrm{mg} / \mathrm{l}$ \\
\hline$P_{\text {tot }}$ & $6 \mathrm{mg} / \mathrm{l}$ & $\mathrm{N}^{-\mathrm{NH}_{4}}{ }^{+}$ & $0.59 \mathrm{mg} / \mathrm{l}$ \\
\hline & & $\mathrm{N}-\mathrm{NO}_{3}^{-}$ & $20 \mathrm{mg} / \mathrm{l}$ \\
\hline & & $\mathrm{N}^{-\mathrm{NO}_{2}}{ }^{-}$ & $0.23 \mathrm{mg} / \mathrm{l}$ \\
\hline & & $\mathrm{P}_{\text {tot }}$ & $1 \mathrm{mg} / \mathrm{l}$ \\
\hline
\end{tabular}

The main operational data (typical values) are: theoretical HRT of the biological reactor $=8.11 \mathrm{~h}$; theoretical HRT of the secondary settling tank $=$ $2.82 \mathrm{~h}$; inlet daily average flow rate $\left(\mathrm{Q}_{24}\right)=56 \mathrm{~m}^{3} / \mathrm{h}$; concentration of dissolved oxygen in the activated sludge tanks $=2.0-2.2 \mathrm{mg} / \mathrm{l}$; total suspended solids concentration in the biological reactors $=3.6 \mathrm{gSST} / \mathrm{l} ; \mathrm{F} / \mathrm{M}=0.16 \mathrm{kgBOD}_{5} /$ $\mathrm{kgSSV}^{*} \mathrm{~d}$. 


\subsection{Hydrodynamic tests}

The verification of functionality of the activated sludge tank and the secondary settler was performed through a hydrodynamic test with Lithium Carbonate $\left(\mathrm{Li}_{2} \mathrm{CO}_{3}\right)$ as tracer, chosen according to its characteristics: negligible pollution potential, negligible natural occurrence in wastewater, high inertia with the process and good instrumental detection.

The choice of sampling points, the implementation of the test, the equations used to generate the experimental data, the data processing (to identify the theoretical model that described the hydrodynamic behaviour of the tanks) were made according to what reported by Collivignarelli et al. [11]. For both tanks, the Lithium Carbonate was introduced in pulse mode and in such quantity as to obtain a theoretical $\mathrm{Li}^{+}$ion concentration in the activated sludge tank equal to $1 \mathrm{mg} / \mathrm{l}$. The sampling points on the activated sludge tank were chosen at input, output and on return sludge line from the secondary settler. The following sampling frequency was adopted: 10 minutes for the first hour, 15 minutes for the next three hours, 30 minutes for the next four hours, 60 minutes for subsequent five hours and 120 minutes for the last eight hours.

Sampling points on the secondary settler were chosen at the input, output and the return sludge line. A sampling frequency of 10 minutes for the first hour, 15 minutes for the following two hours, 15 minutes for the last five hours was adopted.

\subsection{Sample preparation and analysis}

\subsubsection{Endocrine disruptors}

Extraction of Endocrine Disruptors from the liquid phase was conducted according to Liu et al. [12]. The following chemicals were purchased from Sigma Aldrich: (a) analytical standards: Estrone, 17 $\beta$-Estradiol, 17 $\alpha$ Ethinylestradiol, 4-Nonylphenol, Bisphenol A, (b) derivatization reagents: BSTFA (1\% TMCS) and pyridine; (c) internal standards: Estradiol-d3, Bisphenol A-d16.

The derivatized solutions, at room temperature, were analyzed using a gas chromatograph mass spectrometry HP 5973 (Agilent Technologies). Data were acquired in full scan mode (from 50 to $500 \mathrm{~m} / \mathrm{Z}$ ) for quantitative analysis and in selected ion monitoring (SIM) mode for qualitative analysis.

\subsubsection{Drugs of abuse}

Extraction of drugs of abuse from the liquid phase was performed as reported by Castiglioni et al. [13], modified as reported by Saito et al. [14]. The following chemicals were purchased from Chemical Research 2000: (a) analytical standards: Benzoylecgonine, Amphetamine, Methamphetamine, 11nor9carboxy- $\triangle 9$-THC, (b) derivatization reagents: MSTFA, (c) internal standards: Benzoylecgonine-d3, Amphetamine-d6, Methamphetamine-d9, 11 nor- 9carboxy$\Delta$ 9-THC-d3.

The derivatized solutions, at room temperature, were analyzed using a gas chromatograph mass spectrometry HP 5973 (Agilent Technologies). Data were 
acquired in full scan mode (from 40 to $500 \mathrm{~m} / \mathrm{Z}$ ) for quantitative analysis and in selected ion monitoring (SIM) mode for qualitative analysis.

\subsection{Calculations and mass balance}

In order to calculate the removal efficiency, input concentrations to each unit of treatment were related to the output concentration taking into account a lag-time equal to the real HRT, as determined through the hydrodynamic tests.

\section{Results and discussion}

\subsection{Hydrodynamic tests}

The tests showed the presence of dysfunction in both the tanks:

- biological reactor: $9 \%$ of dead volume compared to the total volume of wastewater and $7 \%$ of the bypass flow with respect to the input flow rate;

- secondary settler: $40 \%$ of dead volume compared to the total volume of the wastewater.

The presence of dead volume reduced the volume available to mass exchange, with a consequent reduction of the residence time of wastewater. A real HRT equal to 8 hours for the biological tank (HRTteorical $=8.11$ hours) and equal to 1 hour and 40 minutes for the secondary settler (HRTteorical $=2.82$ hours) was calculated.

\subsection{Removal efficiencies and fate of endocrine disruptors in activated sludge tank}

Figure 1 shows the concentrations of 4-NP, BPA, E1 and EE2 detected in the wastewater incoming the WWTP, in the return sludge line, in the input and in the output from the biological reactor (taking into account the real HRT calculated through the hydrodynamic tests). Moreover, the removal efficiency by the biological reactor has been calculated for each compound.

The input average concentration of 4-NP into the activated sludge tank was equal to about $190 \mathrm{ng} / \mathrm{l}$, influenced in most samples by the concentration of 4-NP in the return sludge line. In the effluent, the concentration detected from 20:00 to 23:00 was greater than the input concentration. This phenomenon can be probably attributed both to the partial degradation of Nonylphenol-1-Ethoxylate (NP1EO) and/or Nonylphenol-2-Ethoxylate (NP2EO) to 4-NP (Soares et al. [15]), and to the release of 4-NP previously adsorbed to the sludge flocs.

Bisphenol $\mathrm{A}$ in the wastewater ranged between $200 \mathrm{ng} / \mathrm{l}$ and $1500 \mathrm{ng} / \mathrm{l}$. The concentration of Bisphenol $\mathrm{A}$ in the return sludge line was almost constant during the investigated period with an average value equal to $40 \mathrm{ng} / \mathrm{l}$. The concentration in the input to the activated sludge tank varied in time with an average value equal to $240 \mathrm{ng} / \mathrm{l}$, while the output was equal to about $60 \mathrm{ng} / \mathrm{l}$. The removal efficiencies were higher than $70 \%$. Negative values of the removal 

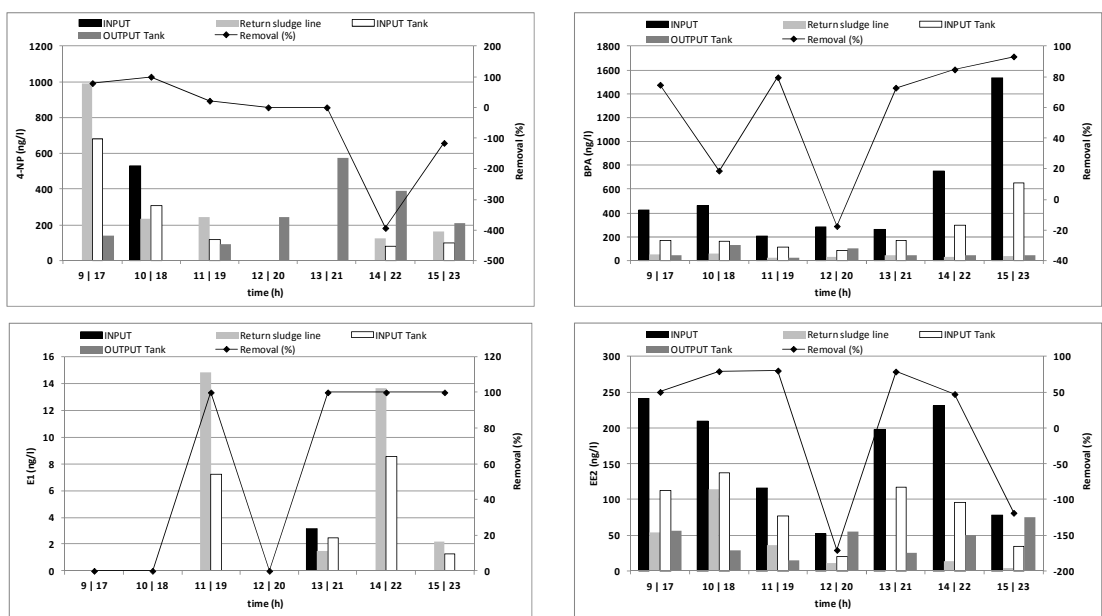

Figure 1: Activated sludge tank: concentrations of the endocrine disrupters (input to WWTP, in the return sludge line, in the input and in the output) and removal efficiencies.

efficiency may be due to the release of BPA previously adsorbed to the flocs, as well as to the hydrodynamic dysfunctions in the reactor (dead volumes and/or bypass flow).

Estrone was measured in the input wastewater only in correspondence to the sampling at 13:00. In the return sludge line E1 was detected in concentrations ranging from approximately $2 \mathrm{ng} / \mathrm{l}$ to $13 \mathrm{ng} / \mathrm{l}$. The output concentrations were always below the Limit of Detection (LOD). The removal efficiencies were, therefore, close to $100 \%$.

Input and output concentrations of $17 \beta$-Estradiol in the bioreactor was not detected in concentrations qualitatively $(<\mathrm{LOD})$ and/or quantitatively $(<\mathrm{LOQ}-$ Limit of Quantification) reliable.

Input concentration of $17 \alpha$-Ethinylestradiol to the WWTP varied during the investigated period, with the highest concentrations in the samples taken at 9:00 and 14:00 (230 ng/l). The average concentration in the return sludge line was equal to $300 \mathrm{ng} / \mathrm{l}$ while input to the activated sludge tank was approximately $85 \mathrm{ng} / \mathrm{l}$. Output concentrations from the biological reactor ranged between approximately $15 \mathrm{ng} / \mathrm{l}$ and $75 \mathrm{ng} / \mathrm{l}$. The removal efficiencies varied between 50 and $80 \%$.

\subsection{Removal efficiencies and fate of drugs of abuse in activated sludge tank}

AM, MET, BEG and THC-COOH (Figure 2) varied over time in the wastewater incoming the WWTP. The maximum inlet concentrations of AM, MET and THC-COOH were equal to 100,16 and $3 \mu \mathrm{g} / 1$, respectively. These concentrations are higher by an order of magnitude compared to the average values reported in literature (Postigo et al. [3]); Huerta-Fontela et al. [16]). 
MET and BEG were detected in the return sludge line in the maximum concentration of about $10 \mu \mathrm{g} / \mathrm{l}$ and approximately $4 \mu \mathrm{g} / \mathrm{l}$, respectively. Concentrations incoming the activated sludge tank (weighted concentrations on the flow rate incoming the WWTP and the return sludge line) varied over time with average values for AM, MET, BEG, and THC-COOH equal to about 40, 4, 3 and $0.5 \mu \mathrm{g} / 1$, respectively.
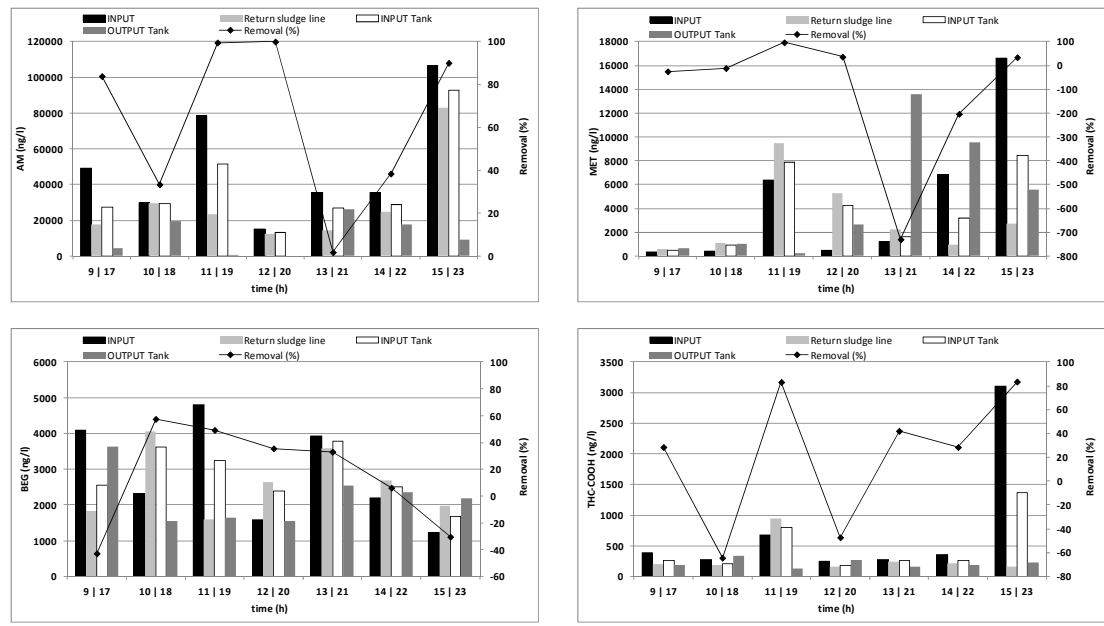

Figure 2: Activated sludge tank: concentrations of the drugs of abuse (input to WWTP, in the return sludge line, in the input and in the output) and removal efficiencies.

Removal efficiencies ranged between 2 and $100 \%$ for AM, 35 and $96 \%$ for MET, 6 and 57\% for the BEG, 28 and $83 \%$ for the THC-COOH. 100\% removal efficiencies indicate the presence of the compound in wastewater incoming the activated sludge tank but not in the corresponding effluent. Negative values of the removal efficiencies indicate a higher presence in the outgoing from the tank compared to the corresponding inlet sample. In the latter case a release of compounds previously adsorbed to the sludge flocs can be suggested.

The highest values of removal efficiencies were calculated for the AM $(100 \%)$, for the MET (96\%) and for THC-COOH (83\%); these values are comparable with the data reported in the literature by several authors (Postigo et al. [3]; Castiglioni et al. [13]; Huerta-Fontela et al. [16]).

\subsection{Removal efficiencies and fate of endocrine disruptors in the secondary settler}

Trend concentrations of endocrine disruptors in the input and in the effluent as well as in the return sludge line are shown in Figure 3, along with the removal efficiencies of each compound. 

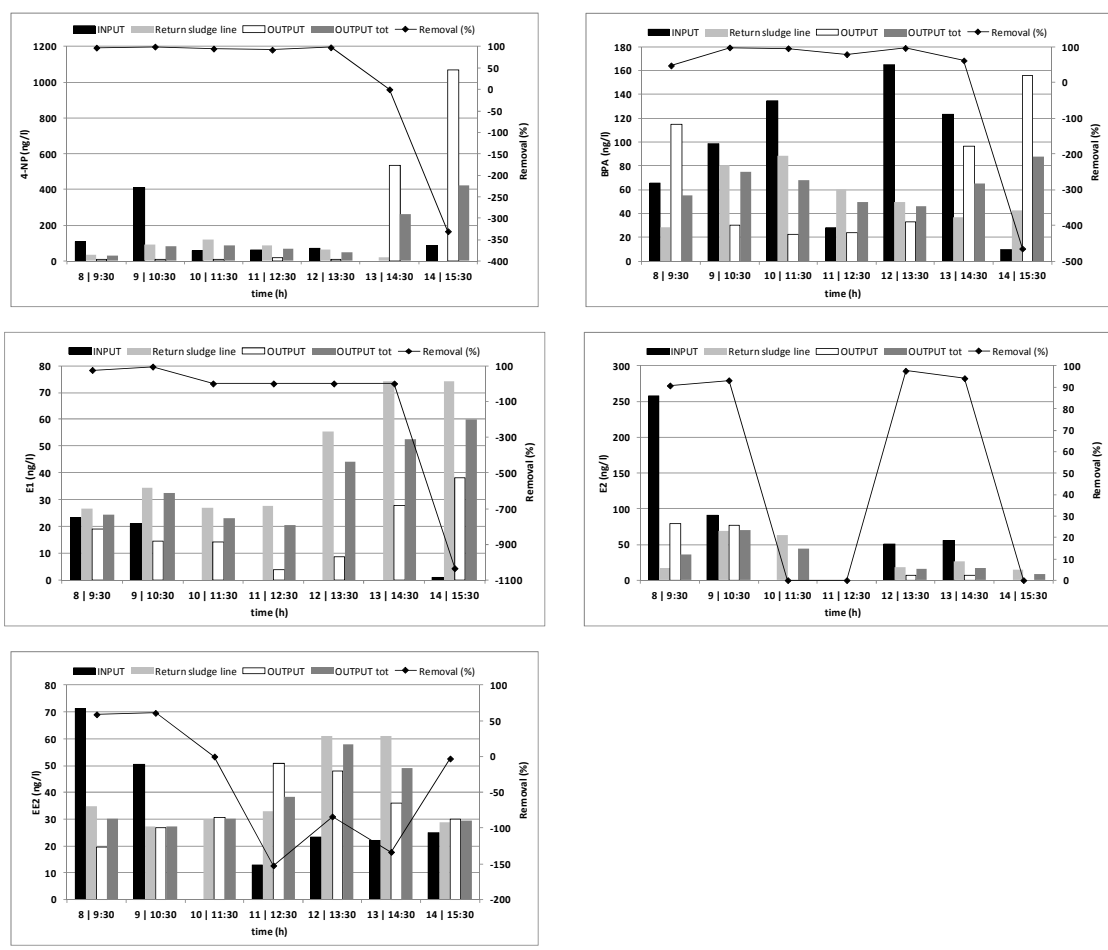

Figure 3: Secondary settler: concentrations of the endocrine disrupters (input, return sludge line and output) and removal efficiencies.

Input concentrations of 4-NP, BPA, E1, E2 and EE2 varied over time: the average concentrations detected in the input of secondary settler were approximately $100 \mathrm{ng} / \mathrm{l}$ for 4-NP, $90 \mathrm{ng} / \mathrm{l}$ for BPA, $7 \mathrm{ng} / \mathrm{l}$ for E1, $65 \mathrm{ng} / \mathrm{l}$ for E2 and $30 \mathrm{ng} / \mathrm{l}$ for EE2. Output concentrations ranged between 7 and $1000 \mathrm{ng} / \mathrm{l}$ for 4-NP, 20 and $150 \mathrm{ng} / \mathrm{l}$ for BPA, 4 and $38 \mathrm{ng} / \mathrm{l}$ for E1, 6 and $80 \mathrm{ng} / \mathrm{l}$ for E2, 19 and $50 \mathrm{ng} / \mathrm{l}$ for EE2. The removal efficiencies of 4-NP were almost constant over time, with mean value equal to $79.5 \%$. This value is comparable with the range of values $(70-92 \%)$ reported in the literature (Nakada et al. [17]).

The removal efficiencies of natural (E1 and E2) and synthetic (EE2) estrogens showed variations in time with maximum values equal to $95 \%$ for E1, $97 \%$ for E2 and $60 \%$ for EE2. Although some literature studies have reported removal efficiency of Estrone approximately equal to 61\% (Johnson and Sumpter [18]), the results of this work are closer to those of Baronti et al. [19].

Output concentrations greater than the input, which results in negative removal efficiencies, can be ascribed to a possible release of the substance previously adsorbed to the sludge flocs. On the basis of such results and given the high value of the octanol-water partition coefficient $\left(\mathrm{K}_{\mathrm{ow}}>4\right)$, Endocrine Disrupters tend to adsorb to sludge flocs but the reverse process cannot be ruled out. 


\subsection{Removal efficiencies and fate of drugs of abuse in the secondary settler}

$\mathrm{AM}, \mathrm{BEG}$ and THC-COOH showed variation in time (Figure 4), with average values of concentrations equal to $5.5 \mu \mathrm{g} / 1,2.3 \mu \mathrm{g} / 1$ and $0.3 \mu \mathrm{g} / \mathrm{l}$, respectively. MET showed a declining trend during the investigated period, with a maximum and minimum concentration of $4 \mu \mathrm{g} / \mathrm{l}$ and $1 \mu \mathrm{g} / \mathrm{l}$, respectively. Similar trend was observed for MET in the return sludge line.
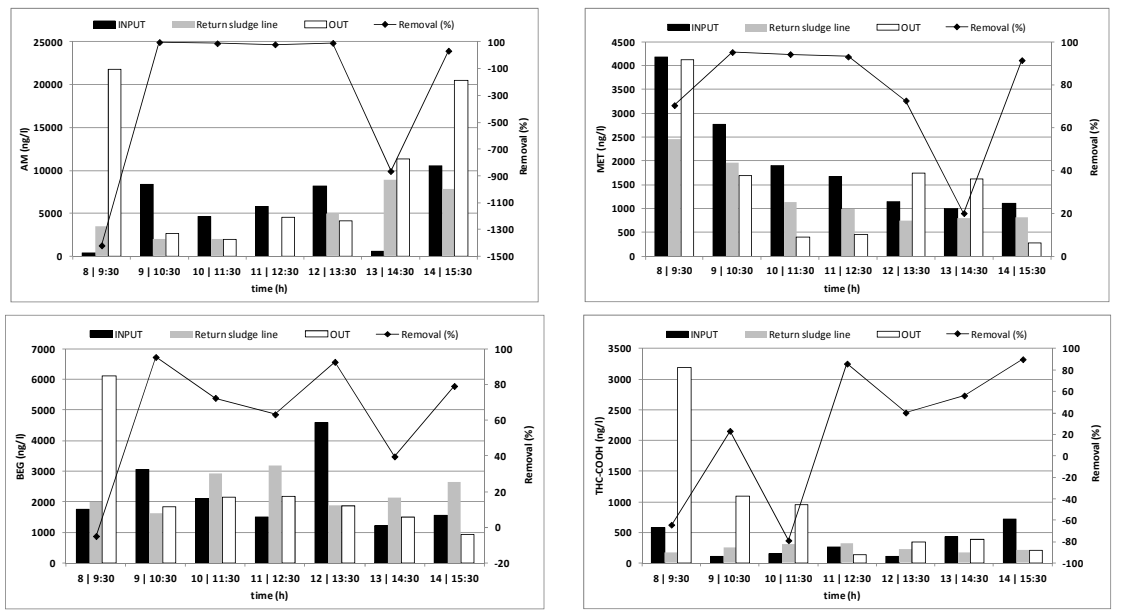

Figure 4: Secondary settler: concentrations of the drugs of abuse (input, return sludge line and output) and removal efficiencies.

AM, MET and THC-COOH outgoing concentrations from secondary settler ranged between 2 and $20 \mu \mathrm{g} / 1,0.4$ and $4 \mu \mathrm{g} / 1,0.1$ and $3 \mu \mathrm{g} / 1$, respectively.

$\mathrm{BEG}$ showed concentration trend in the effluent almost constant in time and equal to $0.5 \mu \mathrm{g} / \mathrm{l}$. AM average removal efficiencies were equal to $90 \%$, except for two samples, in which the output concentration was greater than the inlet concentration (negative removal efficiencies).

AM removal was comparable to literature data reported by different authors: Huerta-Fontala et al. [16] and Postigo et al. [3], have obtained removal efficiencies in the range $50-99 \%$ and $95 \%$, respectively.

MET removal efficiencies ranged between 20-95\%. BEG and THC-COOH removal efficiencies varied, with maximum values equal to $95 \%$ for $\mathrm{BEG}$ and $90 \%$ for THC-COOH. BEG removal was higher than those reported by HuertaFontala et al. [16] (80-88\%).

\subsection{Mass balance}

As shown in Figures 5a and 5b, the mass of 4-NP and MET leaving the biological tank was greater than the input; in the first case is due both to the amount of 4-NP not removed and to the degradation of NP1EO and/or NP2EO, which generate 4-NP, confirming what already discussed. In the second one may 
be ascribed to the release of MET previously adsorbed to the flocs and/or to the presence of hydrodynamic dysfunctions in the activated sludge tank (by-pass flow and dead volumes).
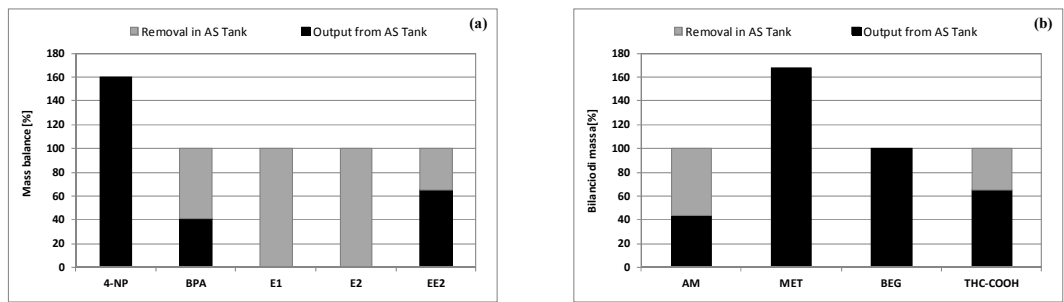

Figure 5: Mass balance of endocrine disrupters (a) and drugs of abuse (b) referred to the activated sludge tank.

E1 and E2 were completely removed in the activated sludge tank. Removal of EE2 and THC-COOH in the activated sludge tank was of about $20 \%$, while BPA and $\mathrm{AM}$ was of about $60 \%$, respectively.

The mass balance on secondary sedimentation tank (Figures 6a-b) showed that none of micropollutants were completely removed. Removal of BPA, E2 and BEG was of about $70 \%$, while E1 and MET was of about $80 \%$, respectively. It is assumed that only the sedimentation process occurred in secondary settler; removed micropollutants, therefore, are distributed between the return sludge line and the excess sludge.

4-NP, THC-COOH and AM were found in greater quantities in the effluent (about $70 \%, 60 \%$ and $50 \%$, respectively).
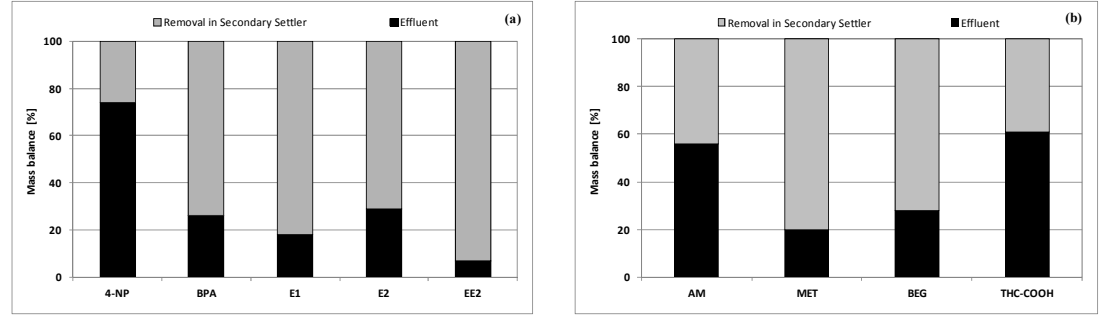

Figure 6: Mass balance of endocrine disrupters (a) and drugs of abuse (b) referred to the secondary settler.

\section{Conclusions}

The monitoring campaign revealed that all the compounds investigated were removed in variable amounts over time in the activated sludge tank and in the secondary settler. In some cases the output concentrations were higher than the input, probably due to the release of previously adsorbed substances by the 
sludge flocs. In the case of 4-NP and THC-COOH this phenomenon can also be ascribed to their generation as metabolites of polyethoxylated nonylphenols (NPnEO) and THC biodegradation.

The mass balance showed that:

- BPA (59\%) and EE2 (35\%) were removed in the activated sludge tank while in the secondary settler all endocrine disrupters are partially removed;

- drugs of abuse were only partially removed in WWTP. The activated sludge tank removed AM (56\%) and THC-COOH (35\%). MET (80\%) and BEG $(72 \%)$ were removed in the secondary settler;

- 4-NP, AM and THC-COOH were found in greater quantities in the effluent (about $70 \%, 50 \%$ and $60 \%$, respectively).

In conclusion, the removal of emerging organic micropollutants in the WWTP studied was only partial, indicating that a conventional WWTP is not able to completely demolish these contaminants, as it was not designed with this purpose. Therefore, these compounds can be found into receiving waters potentially active and dangerous for both human and the environment.

Despite the results obtained, the role of biotic, abiotic and their combination on the removal of these compounds in the biological reactor and in the secondary settling tank is still to be checked.

\section{References}

[1] Mastroianni, N., López de Alda, M. and Barceló. D., Emerging organic contaminants in aquatic environments: state-of-the-art and recent scientific contributions. Contribution to Science, 6(2), pp. 193-197, 2010.

[2] Richardson, SD., Environmental mass spectrometry: emerging contaminants and current issues. Analytical Chemistry, 80, pp. 4373-4402, 2008.

[3] Postigo, C., Lopez de Alda, M.J. and Barcelo D., Drugs of abuse and their metabolites in the Ebro River basin: occurrence in sewage and surface water, sewage treatment plants removal efficiency, and collective drug usage estimation. Environment International, 36, pp. 75-74, 2010.

[4] Stasinakis, A.S., Gatidou, G., Mamais, D., Thomaidis, N.S. and Lekkas, T.D., Occurrence and fate of endocrine disrupters in Greek sewage treatment plants. Water Research, 42, pp. 1796-1804, 2008.

[5] Rosal, R., Rodriguez, A., Perdigón-Melón, J.A., Petre, A., García-Calvo, E., Gómez, M.J., Agüera, A. and Fernández-Alba, A.R., Occurrence of emerging pollutants in urban wastewater and their removal through biological treatment followed by ozonation. Water Research, 44, pp. 578588, 2010.

[6] Ren, Y.X., Nakano, K., Nomura, M., Chiba, N. and Nishimura, O., A thermodynamic analysis on adsorption of estrogens in activated sludge process. Water Research, 41, pp. 2341-2348, 2007.

[7] Dialynas, E. and Diamdopoulos, E., The effect of biomass adsorption on the removal of selected pharmaceutical compounds in an immersed 
membrane bioreactor system. Journal of Chemical Technology \& Biotechnology, DOI 10.1002/jctb.2703, 2011.

[8] Bertanza, G., Pedrazzani, R., Dal Grande, M., Papa, M., Zambarda, V., Montani, C., Steimberg, N., Mazzoleni, G. and Di Lorenzo, D., Effect of biological and chemical oxidation on the removal of estrogenic compounds (NP and BPA) from wastewater: An integrated assessment procedure. Water Research, 45, pp. 2473-2484, 2011.

[9] Cirja, M., Ivashechkin, P., Schäffer, A. and Corvini, P. F. X., Factors affecting the removal of organic micropollutants from wastewater in conventional treatment plants (CTP) and membrane bioreactors (MBR). Reviews in Environmental Science and Biotechnology, 7, pp. 61-78, 2008.

[10] APHA, AWWA, WEF, Standard Method for the examination of water and wastewater (21st Edition). Washington DC, 2005.

[11] Collivignarelli, C., Bertanza, G. and Bina, S., La verifica idrodinamica nel trattamento delle acque. Basi teoriche, Procedure di applicazione, Esempi. Collana Ambiente, vol.8, C.I.P.A. Editore, 1995.

[12] Liu, R., Zhou, J. L. and Wilding, A., Simultaneous determination of endocrine disrupting phenolic compounds and steroids in water by solidphase extraction gas chromatography-mass spectrometry. Journal of Chromatography A, 1022, pp. 179-189, 2004.

[13] Castiglioni, S., Zuccato, E., Chiabrando, C., Fanelli, R. and Bagnati, R., Identification and measurement of illicit drugs and their metabolites in urban wastewater by liquid chromatography-tandem mass spectrometry. Analytical Chemistry, 78, pp. 8421-8429, 2006.

[14] Saito, T., Mase, H., Takeichi, S., Inokuchi, S., Rapid simultaneous determination of ephedrines, amphetamines, cocaine, cocaine metabolites, and opiates in human urine by GC/MS. Journal of Pharmaceutical and Biomedical Analysis, 43, pp. 358-363, 2007.

[15] Soares, A., Guieysse, B., Jefferson, B., Cartmell, E. and Lester, J.N., Nonylphenol in the environment: A critical review on occurrence, fate, toxicity and treatment in wastewaters. Environment International, 34, pp. 1033-1049, 2008.

[16] Huerta-Fontela, M., Galceran, M. T., Martin-Alonso, J. and Ventura, F., Occurrence of psychoactive stimulatory drugs in wastewaters in northeastern Spain. Science of the Total Environment, 397, pp. 31-40, 2008.

[17] Nakada, N., Tanishima, T., Shinohara, H., Kiri, K. and Takada, H. (2006). Pharmaceutical chemicals and endocrine disrupters in municipal wastewater in Tokyo and their removal during activated sludge treatment. Water Research, 40, pp. 3297-3303, 2006.

[18] Johnson, C. and Sumpter, J. P., Removal of Endocrine-Disrupting Chemicals in Activated Sludge Treatment Works. Environmental Science and Technology, 35, pp. 4697-4703, 2000.

[19] Baronti, C., Curini, R., D’Ascenzo, G., Di Corcia, A., Gentili, A. and Samperi, R., Monitoring natural and synthetic estrogens at activated sludge sewage treatment plants and in receiving river water. Environmental Science and Technology, 34, pp. 5059-5066, 2000. 